\title{
Antimicrobial Activity of Telavancin Tested In Vitro Against a Global Collection of Gram-Positive Pathogens, Including Multidrug-Resistant Isolates (2015-2017)
}

\author{
Leonard R. Duncan, Helio S. Sader, Michael D. Huband, Robert K. Flamm, and Rodrigo E. Mendes
}

This study evaluated the in vitro antimicrobial activity of telavancin against a large collection of Gram-positive pathogens of clinical importance, which were collected worldwide from 2015 through 2017, including methicillin-resistant Staphylococcus aureus (MRSA), coagulase-negative staphylococci, Enterococcus spp., $\beta$-hemolytic streptococci (BHS), Streptococcus pneumoniae, and viridans group streptococci (VGS). This report completes 7 years of continuous surveillance data for telavancin using the approved reference method for in vitro testing methodology that includes the addition of polysorbate 80 . For isolates collected from 2015 through 2017, telavancin exhibited potent activity against the following species and groups that have Clinical and Laboratory Standards Institute (CLSI)-approved interpretive criteria: MRSA ( MIC $_{90}$ value, $0.06 \mu \mathrm{g} / \mathrm{mL}$; $100 \%$ susceptible), vancomycin-susceptible Enterococcus faecalis ( $\mathrm{MIC}_{90}$ value, $0.25 \mu \mathrm{g} / \mathrm{mL}$; $99.9 \%$ susceptible), BHS ( $\mathrm{MIC}_{90}$ value, $0.03 \mu \mathrm{g} / \mathrm{mL} ; 100 \%$ susceptible), and VGS ( $\mathrm{MIC}_{90}$ value, $0.03 \mu \mathrm{g} / \mathrm{mL} ; 99.0 \%$ susceptible). Importantly, telavancin maintained excellent antimicrobial activity against multidrug-resistant subsets of these pathogen groups and against ceftaroline-nonsusceptible (telavancin $\mathrm{MIC}_{90}$ value, $0.06 \mu \mathrm{g} / \mathrm{mL} ; 100 \%$ susceptible) and ceftaroline-resistant (telavancin $\mathrm{MIC}_{90}$ value, $0.12 \mu \mathrm{g} / \mathrm{mL} ; 100 \%$ susceptible) S. aureus isolates.

Keywords: telavancin, lipoglycopeptide, multidrug resistant, in vitro testing, global

\section{Introduction}

T ELAVANCIN IS A SEMISYNTHETIC lipoglycopeptide derived from vancomycin that exhibits potent in vitro bactericidal antimicrobial activity against many Grampositive bacterial species of clinical importance, including methicillin-resistant Staphylococcus aureus (MRSA), heterogeneous vancomycin-intermediate $S$. aureus (hVISA), $\beta$ hemolytic streptococci (BHS), viridans group streptococci (VGS), and vancomycin-susceptible enterococci., The antibacterial activity of telavancin is due to 2 independent modes of action that involve the inhibition of peptidoglycan synthesis and depolarization of the cell membrane. ${ }^{3}$

With once-daily parenteral dosing, telavancin is approved in the United States and Canada for the treatment of adults with complicated skin and skin structure infections (cSSSI) or hospital-acquired (HAP)/ventilator-associated (VAP) bacterial pneumonia caused by susceptible isolates of $S$. aureus when alternative treatments are not suitable. ${ }^{4}$ The activity and safety of telavancin in clinical trials have been recently reviewed. ${ }^{5-9}$ Notably, comparable efficacy was demonstrated between telavancin and vancomycin in a limited number of patients with either cSSSI or HAP/VAP and concurrent S. aureus bacteremia. ${ }^{4}$

Global surveillance data on telavancin activity have been collected since 2011 using the current in vitro testing methodology approved by the United States Food and Drug Administration (U.S. FDA), with the most recent report covering isolates collected in $2014 .^{10}$ In this study, we extend these findings by evaluating telavancin in vitro activity against a large worldwide collection of Gram-positive pathogens collected from 2015 through 2017, including multidrug-resistant (MDR) subsets and ceftaroline-nonsusceptible and ceftarolineresistant $S$. aureus isolates.

\section{Materials and Methods}

\section{Bacterial isolates tested}

A total of 24,408 nonduplicate consecutive Gram-positive clinical isolates from the SENTRY Antimicrobial Surveillance Program were submitted from 144 medical centers across 34 countries in North America ( 78 medical centers), Latin America (10 medical centers), Europe (41 medical centers), and the Asia-Pacific region (15 medical centers)

JMI Laboratories, North Liberty, Iowa, USA. 
(Supplementary Table S1). Supplementary Table S2 displays the number of isolates by species stratified by country of collection. Only one isolate per patient infection episode was included in the surveillance collection. Species identification was performed at the participating medical centers and confirmed at JMI Laboratories (North Liberty, IA) using matrix-assisted laser desorption ionization-time of flight mass spectrometry (Bruker, Billerica, MA) when necessary.

The isolates were collected primarily from bloodstream infections (5,184 isolates; $21.2 \%$ overall), skin and skin structure infections $(10,300$ isolates; $42.2 \%$ overall), pneumonia in hospitalized patients (5,156 isolates; $21.1 \%$ overall; this category includes patients hospitalized for any reason, who were diagnosed with pneumonia while hospitalized), urinary tract infections (1,000 isolates; $4.1 \%$ overall), intraabdominal infections (721 isolates; $3.0 \%$ overall), communityacquired respiratory tract infection (1,045 isolates; $4.3 \%$ overall), and other infections (1,002 isolates; $4.1 \%$ overall), according to a standard surveillance design.

Table 1 lists the number of isolates collected per year for each major species and organism group. A total of 49 isolates were part of low prevalence species and were not considered further in this study. In 2017, the surveillance design for telavancin was restricted to the collection of $S$. aureus isolates from the United States (Table 1).

Minimal inhibitory concentration (MIC) values were also measured for 2 supplemental groups of $S$. aureus isolates, which were used to enrich the set of 484 ceftarolinenonsusceptible $S$. aureus isolates collected from 2015 through 2017 as part of the SENTRY surveillance program for telavancin. First, a set of 50 randomly selected ceftarolinenonsusceptible (MIC $\geq 2 \mu \mathrm{g} / \mathrm{mL}$ ) S. aureus isolates collected in 2017 from Europe $(n=27)$, Latin America $(n=11)$, and the Asia-Pacific region $(n=12)$ was added to the SENTRY telavancin surveillance isolates to generate a combined set of 534 ceftaroline-nonsusceptible $S$. aureus isolates (Table 2). MIC values were also measured for a second set of 35 ceftaroline-resistant (MIC $\geq 4 \mu \mathrm{g} / \mathrm{mL}$ ) S. aureus isolates that were collected globally from 2015 through 2017 (Table 2).

An isolate was considered MDR if it was nonsusceptible to $\geq 3$ of the antimicrobials listed in Supplementary Table S3 (using Clinical and Laboratory Standards Institute [CLSI] interpretive criteria, where applicable). In general, these MDR definitions were patterned after the recommendations of Magiorakos et al. ${ }^{11}$ which were specified in that report; in this study, the definition was more restrictive for the MRSA subset, which was required to be nonsusceptible to $\geq 3$ of the listed antimicrobials, in addition to oxacillin.

\section{Susceptibility testing methods}

Isolates were tested for antimicrobial susceptibility using broth microdilution methodology as per CLSI guidelines using frozen-form 96-well MIC panels. ${ }^{12}$ The testing medium was cation-adjusted Mueller-Hinton broth supplemented with 2.5-5\% lysed horse blood for testing streptococci, supplemented with $50 \mathrm{mg} / \mathrm{L}$ calcium $\left(\mathrm{Ca}^{2+}\right)$ for testing daptomycin, and supplemented with $0.002 \%$ polysorbate 80 for testing telavancin. ${ }^{12,13}$ MIC results for telavancin and comparators were interpreted using CLSI and European Committee on Antimicrobial Susceptibility Testing (EUCAST) breakpoint criteria, where published. ${ }^{14,15}$
Table 1. Number of Isolates from Selected Species and Groups Collected by Year

\begin{tabular}{|c|c|c|c|c|}
\hline \multirow[b]{2}{*}{ Species/group } & \multicolumn{4}{|c|}{ No. of isolates ${ }^{\mathrm{a}}$} \\
\hline & 2015 & 2016 & 2017 & Total \\
\hline Staphylococcus aureus & 7,025 & 7,096 & 3,511 & 17,632 \\
\hline MRSA & 3,136 & 3,176 & 1,517 & 7,829 \\
\hline MSSA & 3,889 & 3,920 & 1,994 & 9,803 \\
\hline $\mathrm{CoNS}^{\mathrm{b}}$ & 423 & 600 & & 1,023 \\
\hline Enterococcus faecalis & 473 & 684 & & 1,157 \\
\hline Enterococcus faecium & 360 & 299 & & 659 \\
\hline$\beta$-hemolytic streptococci ${ }^{\mathrm{c}}$ & 1,138 & 701 & & 1,839 \\
\hline Streptococcus pneumoniae & 531 & 701 & & 1,232 \\
\hline $\begin{array}{l}\text { Viridans group } \\
\text { streptococci }\end{array}$ & 300 & 517 & & 817 \\
\hline Total & 10,250 & 10,598 & 3,511 & 24,359 \\
\hline
\end{tabular}

${ }^{\mathrm{a} N o t}$ listed are 49 isolates of low prevalence species.

borganisms included Staphylococcus arlettae (1), Staphylococcus auricularis (2), Staphylococcus capitis (56), Staphylococcus caprae (13), Staphylococcus cohnii (4), Staphylococcus condimenti (1), Staphylococcus epidermidis (569), Staphylococcus felis (1), Staphylococcus haemolyticus (72), Staphylococcus hominis (89), Staphylococcus intermedius (2), Staphylococcus lugdunensis (134), Staphylococcus pasteuri (1), Staphylococcus petrasii (1), Staphylococcus pettenkoferi (11), Staphylococcus pseudintermedius (4), Staphylococcus pseudintermedius/intermedius/delphini (1), Staphylococcus saprophyticus (30), Staphylococcus schleiferi (5), Staphylococcus simulans (12), Staphylococcus warneri (12), Staphylococcus xylosus (1), and unspeciated CoNS (1).

'Organisms included Streptococcus agalactiae (772), Streptococcus canis (2), Streptococcus dysgalactiae (249), Streptococcus equi (2), and Streptococcus pyogenes (814).

${ }^{\mathrm{d}}$ Organisms included Streptococcus anginosus (203), S. anginosus group (49), Streptococcus australis (4), Streptococcus bovis group (4), Streptococcus constellatus (31), Streptococcus cristatus (6), Streptococcus equinus (2), Streptococcus gallolyticus (44), Streptococcus gordonii (15), Streptococcus infantarius (1), Streptococcus infantis (4), Streptococcus intermedius (27), Streptococcus lutetiensis (13), Streptococcus massiliensis (3), Streptococcus mitis (8), Streptococcus mitis group (160), Streptococcus mitis/oralis (63), Streptococcus mutans (4), Streptococcus oralis (37), Streptococcus parasanguinis (58), Streptococcus salivarius (15), Streptococcus salivarius group (17), Streptococcus salivarius/vestibularis (12), Streptococcus sanguinis (30), and Streptococcus vestibularis (7).

CoNS, coagulase-negative staphylococci; MRSA, methicillinresistant $S$. aureus; MSSA, methicillin-susceptible $S$. aureus.

Concurrently tested American Type Culture Collection (ATCC) quality control strains included $S$. aureus ATCC 29213, Enterococcus faecalis ATCC 29212, and Streptococcus pneumoniae ATCC 49619. The inoculum densities during susceptibility testing were monitored by bacterial colony counts.

\section{Results}

\section{Telavancin and comparator activities against S. aureus}

Telavancin exhibited $\mathrm{MIC}_{90}$ values of $0.06 \mu \mathrm{g} / \mathrm{mL}$ against the full global set of $S$. aureus isolates and the MRSA subset (44.4\% of the full set), and all isolates were susceptible to telavancin (Table 2). The $\mathrm{MIC}_{50 / 90}$ results for telavancin tested against the full $S$. aureus isolate set were identical to results from global surveillance data derived from isolates collected from 2011 through $2014 .{ }^{10,16-19}$ For 


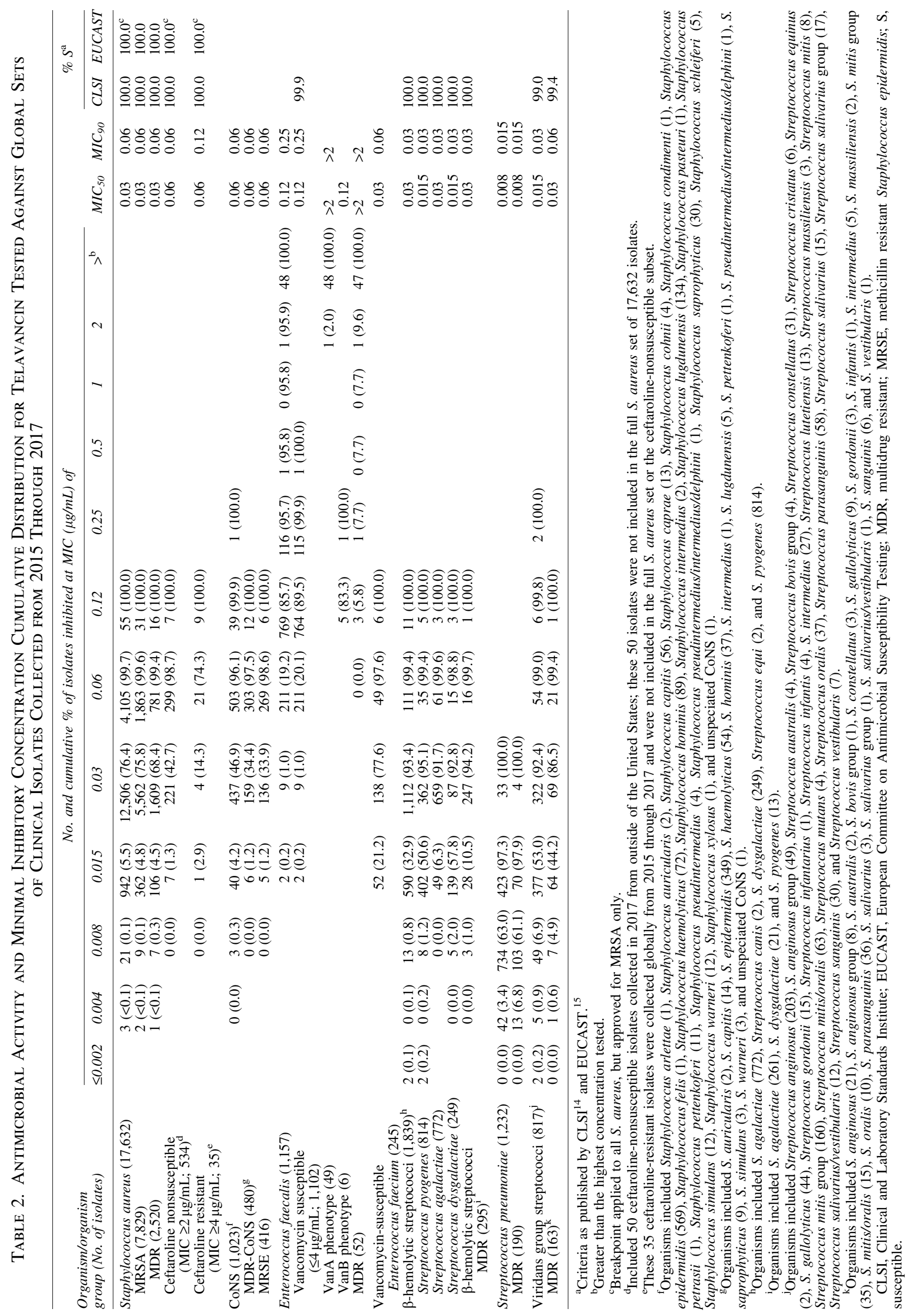


the full $S$. aureus isolate set, telavancin activity did not vary by continent; the $\mathrm{MIC}_{50}$ value increased twofold to $0.06 \mu \mathrm{g} / \mathrm{mL}$ for MRSA isolates from Latin American (data not shown).

MIC data for comparator antimicrobials tested against the full $S$. aureus and MRSA isolate sets are shown in Table 3. No VISA isolates were observed in this study. In total, $2.7 \%$ of the $S$. aureus isolates were nonsusceptible to ceftaroline, but this value increased to $6.2 \%$ among the MRSA subset (Table 3).

We further explored the antimicrobial activities of telavancin and comparator agents by testing subsets of $S$. aureus isolates that were ceftaroline nonsusceptible or ceftaroline resistant (see Materials and Methods section) (Tables 2 and 4). The telavancin $\mathrm{MIC}_{90}$ values were identical for the full $S$. aureus and ceftaroline-nonsusceptible $S$. aureus isolate sets (both $\mathrm{MIC}_{90}$ values, $0.06 \mathrm{mg} / \mathrm{mL}$ ), only increased twofold ( $\mathrm{MIC}_{90}$ value, $0.12 \mathrm{mg} / \mathrm{mL}$ ) against the ceftarolineresistant subset, and all isolates remained susceptible to telavancin (Table 2). In addition to telavancin, the ceftarolinenonsusceptible and ceftaroline-resistant $S$. aureus subsets were also highly susceptible ( $97.2 \%$ to $100 \%)$ to daptomycin, linezolid, trimethoprim-sulfamethoxazole, and vancomycin (Table 4).
Notably, the telavancin MIC $_{90}$ value and susceptibility rate for the MDR MRSA subset were identical to the corresponding values for the full isolate set (Table 2). In addition to telavancin, the MDR MRSA subset was $>90 \%$ susceptible to daptomycin, linezolid, teicoplanin, trimethoprim-sulfamethoxazole, and vancomycin (Table 5). Overall, the MDR MRSA subset was $81.8 \%$ susceptible to ceftaroline, but this activity varied by geographical region from a low of $39.1 \%$ susceptible in the Asia-Pacific to a high of $85.7 \%$ susceptible in North America (Fig. 1). A similar trend of lower ceftaroline susceptibility among isolates from the Asia-Pacific and Latin American regions was also observed for the full MRSA subset (North America, 95.6\% susceptible; Europe, 89.4\% susceptible; Asia-Pacific, $72.8 \%$ susceptible; and Latin America, $76.1 \%$ susceptible) (data not shown).

\section{Telavancin and comparator activities against coagulase-negative staphylococci}

Telavancin exhibited potent activity $\left(\mathrm{MIC}_{90}\right.$ value, $0.06 \mu \mathrm{g} / \mathrm{mL}$ ) against the full set of coagulase-negative staphylococci (CoNS) isolates, the methicillin-resistant Staphylococcus epidermidis subset, and the MDR CoNS subset (Table 2), and these results were similar or identical

Table 3. Antimicrobial Activity of Telavancin and Comparator Agents Tested Against the Full STAPHYLOCOCCUS AUREUS AND MethicIllin-RESISTANT STAPHYLOCOCCUS AUREUS Clinical IsOlate SETS Collected From 2015 Through 2017

\begin{tabular}{|c|c|c|c|c|c|c|c|c|c|}
\hline \multirow{2}{*}{$\begin{array}{l}\text { Organism group, } \\
\text { antimicrobial agent }\end{array}$} & \multicolumn{3}{|c|}{$M I C(\mu g / m L)$} & \multicolumn{3}{|c|}{$C L S I^{\mathrm{a}}$} & \multicolumn{3}{|c|}{$E U C A S T^{\mathrm{a}}$} \\
\hline & $M I C_{50}$ & $M I C_{90}$ & Range & $\% S$ & $\% I$ & $\% R$ & $\% S$ & $\% I$ & $\% R$ \\
\hline \multicolumn{10}{|l|}{ S. aureus $(n=17,632)$} \\
\hline Telavancin & 0.03 & 0.06 & $\leq 0.004$ to 0.12 & 100.0 & & & 100.0 & & $0.0^{\mathrm{b}}$ \\
\hline Ceftaroline & 0.25 & 1 & $\leq 0.06$ to $>8$ & 97.3 & 2.7 & $<0.1$ & 97.3 & 2.7 & $<0.1^{\mathrm{c}}$ \\
\hline Clindamycin & $\leq 0.25$ & $>2$ & $\leq 0.25$ to $>2$ & 85.0 & 0.3 & 14.8 & 84.8 & 0.2 & 15.0 \\
\hline Daptomycin & 0.25 & 0.5 & $\leq 0.12$ to 2 & $>99.9$ & & & $>99.9$ & & $<0.1$ \\
\hline Erythromycin & 4 & $>8$ & $\leq 0.06$ to $>8$ & 46.2 & 5.4 & 48.3 & 46.8 & 2.2 & 51.0 \\
\hline Gentamicin & $\leq 1$ & $\leq 1$ & $\leq 1$ to $>8$ & 96.3 & 0.2 & 3.5 & 96.1 & & 3.9 \\
\hline Levofloxacin & 0.25 & $>4$ & $\leq 0.03$ to $>4$ & 63.2 & 0.8 & 36.0 & 63.2 & & 36.8 \\
\hline Linezolid & 1 & 1 & $\leq 0.12$ to $>8$ & $>99.9$ & & $<0.1$ & $>99.9$ & & $<0.1$ \\
\hline Oxacillin & 1 & $>2$ & $\leq 0.25$ to $>2$ & 55.6 & & 44.4 & 55.6 & & 44.4 \\
\hline Teicoplanin & $\leq 0.5$ & $\leq 0.5$ & $\leq 0.5$ to 8 & 100.0 & 0.0 & 0.0 & 99.8 & & 0.2 \\
\hline Tetracycline & $\leq 0.5$ & $\leq 0.5$ & $\leq 0.5$ to $>8$ & 94.2 & 0.9 & 4.9 & 92.8 & 0.6 & 6.6 \\
\hline Trimethoprim-sulfamethoxazole & $\leq 0.5$ & $\leq 0.5$ & $\leq 0.5$ to $>4$ & 98.5 & & 1.5 & 98.5 & 0.2 & 1.3 \\
\hline Vancomycin & 0.5 & 1 & $\leq 0.12$ to 2 & 100.0 & 0.0 & 0.0 & 100.0 & & 0.0 \\
\hline \multicolumn{10}{|l|}{$\operatorname{MRSA}(n=7,829)$} \\
\hline Telavancin & 0.03 & 0.06 & $\leq 0.004$ to 0.12 & 100.0 & & & 100.0 & & 0.0 \\
\hline Ceftaroline & 0.5 & 1 & 0.12 to $>8$ & 93.8 & 6.1 & 0.1 & 93.8 & 6.1 & $0.1^{\mathrm{c}}$ \\
\hline Clindamycin & $\leq 0.25$ & $>2$ & $\leq 0.25$ to $>2$ & 71.4 & 0.3 & 28.3 & 71.2 & 0.1 & 28.6 \\
\hline Daptomycin & 0.25 & 0.5 & $\leq 0.12$ to 2 & $>99.9$ & & & $>99.9$ & & $<0.1$ \\
\hline Erythromycin & $>8$ & $>8$ & $\leq 0.06$ to $>8$ & 17.3 & 4.2 & 78.4 & 17.7 & 1.4 & 80.9 \\
\hline Gentamicin & $\leq 1$ & $\leq 1$ & $\leq 1$ to $>8$ & 93.6 & 0.2 & 6.2 & 93.4 & & 6.6 \\
\hline Levofloxacin & 4 & $>4$ & 0.06 to $>4$ & 29.4 & 1.4 & 69.2 & 29.4 & & 70.6 \\
\hline Linezolid & 1 & 1 & $\leq 0.12$ to $>8$ & $>99.9$ & & $<0.1$ & $>99.9$ & & $<0.1$ \\
\hline Teicoplanin & $\leq 0.5$ & $\leq 0.5$ & $\leq 0.5$ to 8 & 100.0 & 0.0 & 0.0 & 99.6 & & 0.4 \\
\hline Tetracycline & $\leq 0.5$ & 1 & $\leq 0.5$ to $>8$ & 91.7 & 1.0 & 7.3 & 90.3 & 1.0 & 8.8 \\
\hline Trimethoprim-sulfamethoxazole & $\leq 0.5$ & $\leq 0.5$ & $\leq 0.5$ to $>4$ & 97.1 & & 2.9 & 97.1 & 0.5 & 2.4 \\
\hline Vancomycin & 0.5 & 1 & $\leq 0.12$ to 2 & 100.0 & 0.0 & 0.0 & 100.0 & & 0.0 \\
\hline
\end{tabular}

${ }^{\mathrm{a}}$ Criteria as published by $\mathrm{CLSI}^{14}$ and EUCAST. ${ }^{15}$

${ }^{\mathrm{b}}$ Breakpoint applied to all $S$. aureus, but approved for MRSA isolates only.

${ }^{\mathrm{c}}$ Using other than pneumonia breakpoints. 
Table 4. Antimicrobial Activity of Telavancin and Comparator Agents Tested Against Ceftaroline-Nonsusceptible and Ceftaroline-Resistant Staphylococcus aureus Clinical Isolates COLleCted From 2015 Through 2017

\begin{tabular}{|c|c|c|c|c|c|c|c|c|c|}
\hline \multirow{2}{*}{$\begin{array}{l}\text { Organism group, } \\
\text { antimicrobial agent }\end{array}$} & \multicolumn{3}{|c|}{$M I C(\mu g / m L)$} & \multicolumn{3}{|c|}{$C L S I^{\mathrm{a}}$} & \multicolumn{3}{|c|}{$E U C A S T^{\mathrm{a}}$} \\
\hline & $M I C_{50}$ & $M I C_{90}$ & Range & $\% S$ & $\% I$ & $\% R$ & $\% S$ & $\% I$ & $\% R$ \\
\hline \multicolumn{10}{|c|}{ Ceftaroline-nonsusceptible $S$. aureus (MIC $\geq 2 \mu \mathrm{g} / \mathrm{mL}, n=534)^{\mathrm{b}}$} \\
\hline Telavancin & 0.06 & 0.06 & 0.015 to 0.12 & 100.0 & & & 100.0 & & $0.0^{\mathrm{c}}$ \\
\hline Ceftaroline & 2 & 2 & 2 to $>8$ & 0.0 & 98.9 & 1.1 & 0.0 & 98.9 & $1.1^{\mathrm{d}}$ \\
\hline Clindamycin & $>2$ & $>2$ & $\leq 0.25$ to $>2$ & 28.5 & 0.4 & 71.2 & 28.5 & 0.0 & 71.5 \\
\hline Daptomycin & 0.5 & 0.5 & $\leq 0.12$ to 1 & 100.0 & & & 100.0 & & 0.0 \\
\hline Erythromycin & $>8$ & $>8$ & $\leq 0.06$ to $>8$ & 8.1 & 2.2 & 89.7 & 8.2 & 0.9 & 90.8 \\
\hline Gental & $\leq 1$ & $>8$ & $\leq 1$ to $>8$ & 69.3 & 0.0 & 30.7 & 69.1 & & 30.9 \\
\hline Levofloxacin & $>4$ & $>4$ & 0.12 to $>4$ & 0.4 & 0.0 & 99.6 & 0.4 & & 99.6 \\
\hline Linezo & 1 & 2 & 0.25 to 2 & 100.0 & & 0.0 & 100.0 & & 0.0 \\
\hline Oxacillin & $>2$ & $>2$ & $>2$ to $>2$ & 0.0 & & 100.0 & 0.0 & & 100.0 \\
\hline Teic & $\leq 0.5$ & 1 & $\leq 0.5$ to 8 & 100.0 & 0.0 & 0.0 & 96.1 & & 3.9 \\
\hline Tetra & $\leq 0.5$ & $>8$ & $\leq 0.5$ to $>8$ & 85.2 & 0.0 & 14.8 & 74.9 & 9.2 & 15.9 \\
\hline m-sulfamethoxazole & $\leq 0.5$ & $\leq 0.5$ & $\leq 0.5 \mathrm{t}$ & 97.2 & & 2.8 & 97.2 & 0.4 & 2.4 \\
\hline Vancomycin & 1 & 1 & $\leq 0.12$ to 2 & 100.0 & 0.0 & 0.0 & 100.0 & & 0.0 \\
\hline \multicolumn{10}{|c|}{ Ceftaroline-resistant $S$. aureus $(\mathrm{MIC} \geq 4 \mu \mathrm{g} / \mathrm{mL}, n=35)^{\mathrm{e}}$} \\
\hline Telavancin & 0.06 & 0.12 & 0.015 to 0.12 & 100.0 & & & 100.0 & & $0.0^{\mathrm{c}}$ \\
\hline Ceftar & 4 & $>8$ & 4 to $>8$ & 0.0 & 0.0 & 100.0 & 0.0 & 0.0 & $100.0^{\mathrm{d}}$ \\
\hline Clinda & $>2$ & $>2$ & $\leq 0.25$ to $>2$ & 2.9 & 0.0 & 97.1 & 2.9 & 0.0 & 97.1 \\
\hline Dapto & 0.5 & 0.5 & 0.25 to 1 & 100.0 & & & 100.0 & & 0.0 \\
\hline Eryth & $>8$ & $>8$ & 0.12 to $>8$ & 2.9 & 0.0 & 97.1 & 2.9 & 0.0 & 97.1 \\
\hline Genta & $>8$ & $>8$ & $\leq 1$ to $>8$ & 14.3 & 0.0 & 85.7 & 14.3 & & 85.7 \\
\hline Levof & $>4$ & $>4$ & $>4$ to $>4$ & 0.0 & 0.0 & 100.0 & 0.0 & & 100.0 \\
\hline Linez & 1 & 1 & 0.25 to 4 & 100.0 & & 0.0 & 100.0 & & 0.0 \\
\hline Oxaci & $>2$ & $>2$ & $>2$ to $>2$ & 0.0 & & 100.0 & 0.0 & & 100.0 \\
\hline Teico & 2 & 4 & $\leq 0.5$ to 8 & 100.0 & 0.0 & 0.0 & 60.0 & & 40.0 \\
\hline Tetrac & 1 & $>8$ & $\leq 0.5$ to $>8$ & 54.3 & 0.0 & 45.7 & 51.4 & 0.0 & 48.6 \\
\hline Trime & $\leq 0.5$ & $\leq 0.5$ & $\leq 0.5$ to 2 & 100.0 & & 0.0 & 100.0 & 0.0 & 0.0 \\
\hline Vancomycin & 1 & 1 & 0.5 to 2 & 100.0 & 0.0 & 0.0 & 100.0 & & 0.0 \\
\hline
\end{tabular}

${ }^{\mathrm{a}}$ Criteria as published by $\mathrm{CLSI}^{14}$ and EUCAST. ${ }^{15}$

${ }^{\mathrm{b}}$ Randomly selected isolates (see Materials and Methods section).

${ }^{c}$ Breakpoint applied to all $S$. aureus, but approved for MRSA isolates only.

${ }^{\mathrm{d}}$ Using other than pneumonia breakpoints.

${ }^{\mathrm{e}}$ Nonrandomly selected isolates.

I, intermediate; R, resistant.

to corresponding surveillance data reported for isolates collected from 2011 through 2014. ${ }^{10,16-19}$ The telavancin $\mathrm{MIC}_{50 / 90}$ values for the CoNS isolates were identical for all regions studied (data not shown). MIC data for comparator antimicrobials tested against the full CoNS isolate set are shown in Supplementary Table S4. The MDR CoNS subset was $\geq 89.8 \%$ susceptible to daptomycin, linezolid, teicoplanin, and vancomycin, but telavancin was at least eightfold more potent by $\mathrm{MIC}_{50 / 90}$ values than any of these comparator agents (Table 5).

\section{Telavancin and comparator activities against the enterococci}

The overall vancomycin resistance rate was $4.8 \%$ for the set of E. faecalis isolates (Supplementary Table S4). Telavancin exhibited potent antimicrobial activity ( $\mathrm{MIC}_{90}$ value, $0.25 \mu \mathrm{g} / \mathrm{mL}$ ) against the full E. faecalis isolate set (Table 2), and by $\mathrm{MIC}_{90}$ value, telavancin was fourfold to eightfold more potent than ampicillin $\left(\mathrm{MIC}_{90}\right.$ value, $\left.1 \mu \mathrm{g} / \mathrm{mL}\right)$, daptomycin $\left(\mathrm{MIC}_{90}\right.$ value, $1 \mu \mathrm{g} / \mathrm{mL}$ ), linezolid, $\left(\mathrm{MIC}_{90}\right.$ value,
$2 \mu \mathrm{g} / \mathrm{mL}$ ), and vancomycin ( $\mathrm{MIC}_{90}$ value, $2 \mu \mathrm{g} / \mathrm{mL}$ ) (Supplementary Table S4). The telavancin $\mathrm{MIC}_{90}$ value against the vancomycin-susceptible E. faecalis subset was unchanged compared to the full isolate set (Table 2). The $\mathrm{MIC}_{90}$ value reported for the vancomycin-susceptible $E$. faecalis isolates tested in this study $\left(\mathrm{MIC}_{90}\right.$ value, $0.25 \mu \mathrm{g} / \mathrm{mL}$ ) was similar to that reported for isolates collected from 2011 to

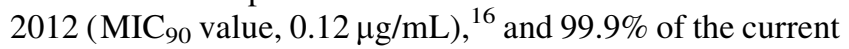
vancomycin-susceptible isolates remained susceptible to telavancin (Table 2).

All 49 E. faecalis isolates with telavancin MIC values of $\geq 2 \mu \mathrm{g} / \mathrm{mL}$ exhibited a VanA resistance phenotype (Table 2). In contrast, telavancin retained activity against the subset of 6 isolates that exhibited a VanB resistance phenotype (telavancin MIC range, $0.12-0.25 \mu \mathrm{g} / \mathrm{mL}$ ) (Table 2). Telavancin activity was lower against the subset of 52 MDR E. faecalis isolates $\left(\mathrm{MIC}_{90}\right.$ value, $>2 \mu \mathrm{g} / \mathrm{mL}$ ), because the subset was $100 \%$ resistant to vancomycin and predominately exhibited a VanA phenotype (Table 2 and data not shown). The MDR E. faecalis subset remained $100 \%$ susceptible to ampicillin, daptomycin, and linezolid (data not shown). 


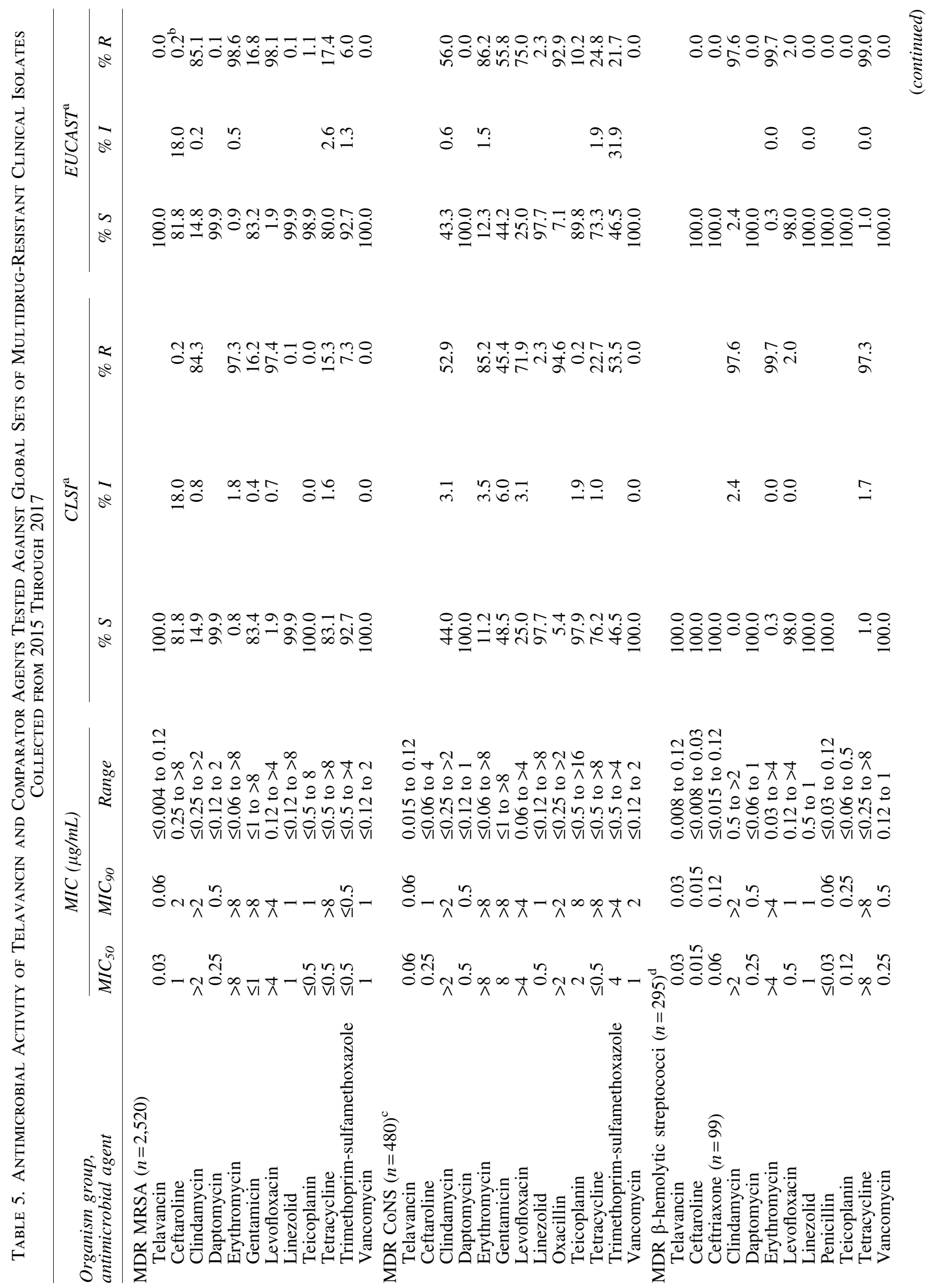




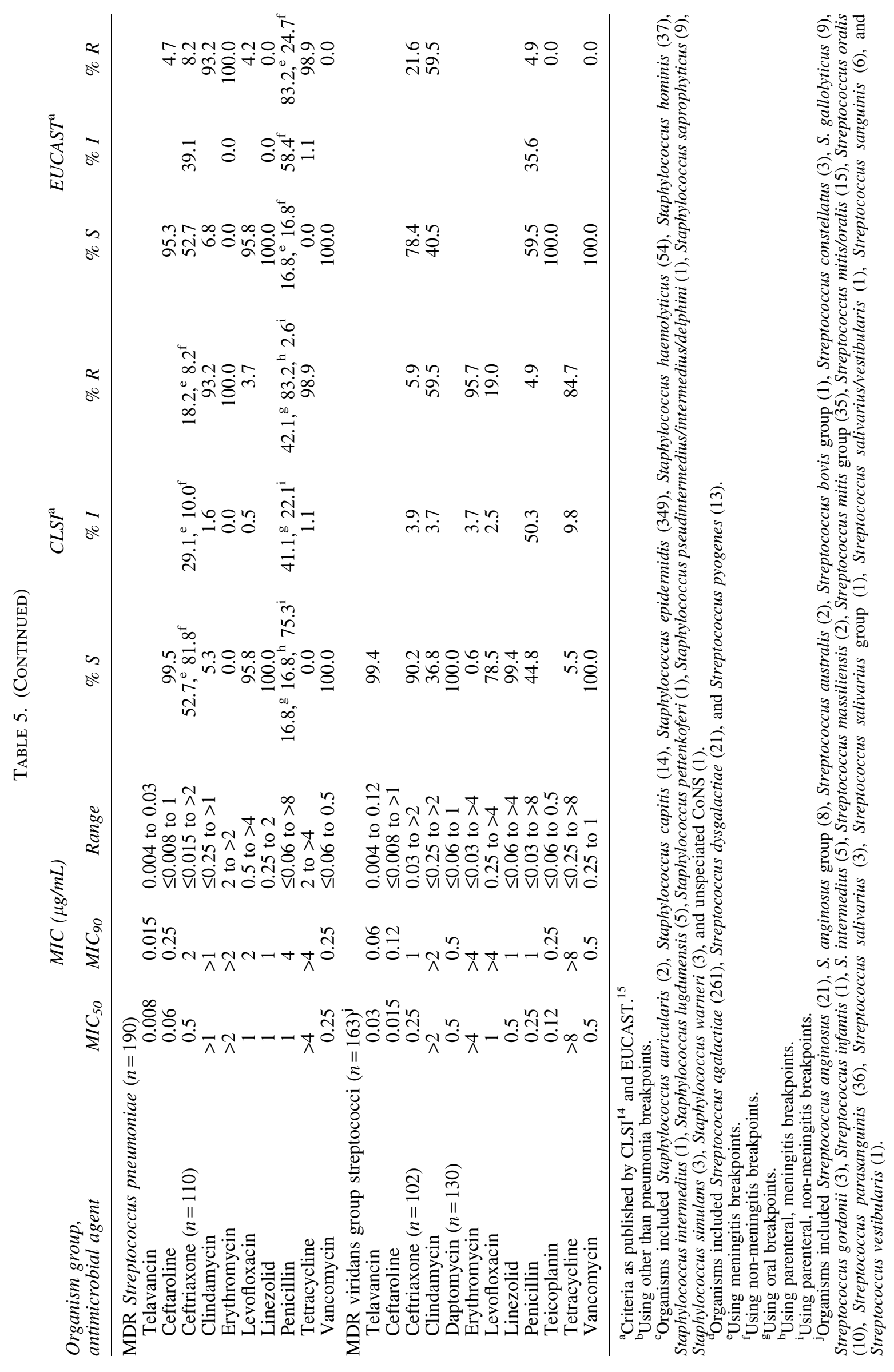




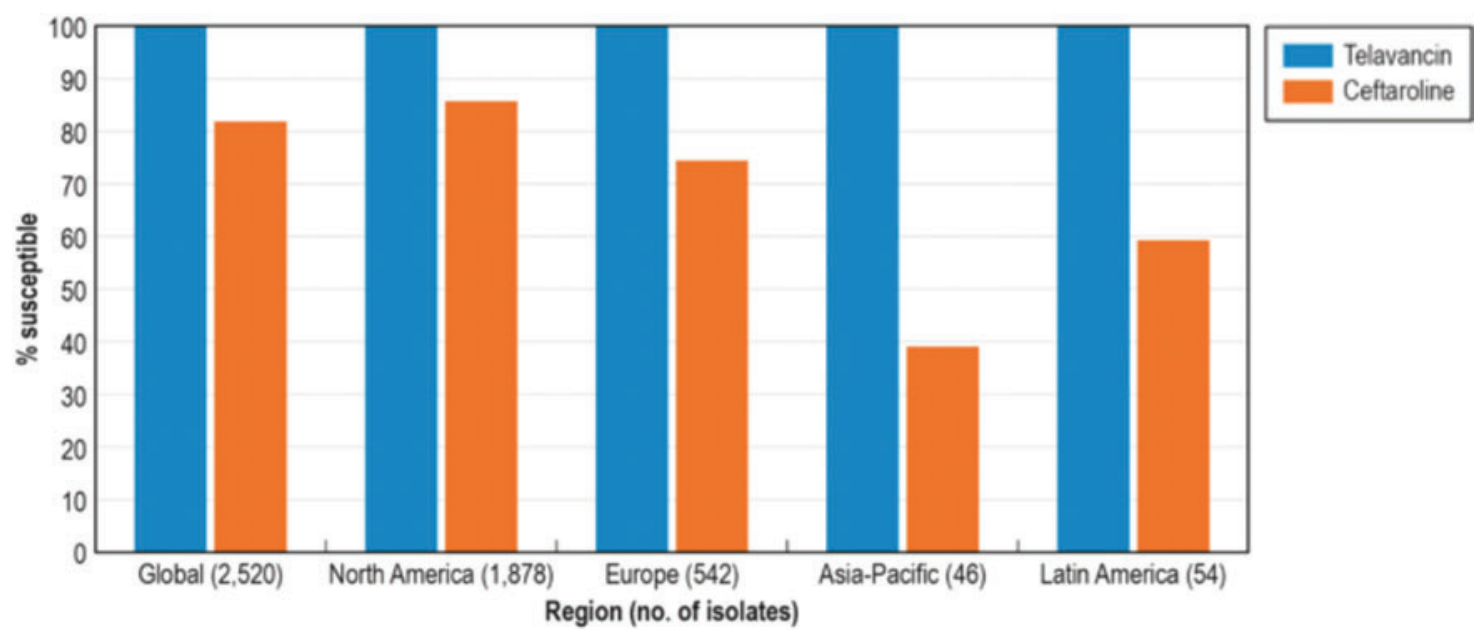

FIG. 1. Telavancin and ceftaroline activity against multidrug-resistant MRSA isolates collected from 2015 through 2017 stratified by global region. MRSA, methicillin-resistant Staphylococcus aureus. Color images are available online.

Most Enterococcus faecium isolates were resistant to vancomycin (62.1\% resistant) (Supplementary Table S4). As expected, telavancin exhibited weak activity against the full E. faecium isolate set $\left(\mathrm{MIC}_{90}\right.$ value, $>2 \mu \mathrm{g} / \mathrm{mL}$ ) (Supplementary Table S4), but exhibited potent activity against the vancomycin-susceptible subset ( $\mathrm{MIC}_{90}$ value, $0.06 \mu \mathrm{g} / \mathrm{mL}$ ) (Table 2).

\section{Telavancin and comparator activities against \\ S. pneumoniae}

Telavancin was highly active against the full $S$. pneumoniae isolate set ( $\mathrm{MIC}_{90}$ value, $0.015 \mu \mathrm{g} / \mathrm{mL}$ ) (Table 2), and this activity was unchanged when compared to data from global isolates collected between 2011 and 2014 . $^{10,16,18,19}$ MIC data for comparator antimicrobials tested against the full $S$. pneumoniae isolate set are shown in Supplementary Table S4. The MDR subset of $S$. pneumoniae isolates exhibited decreased susceptibility to ceftriaxone (18.2\% nonsusceptible using non-meningitis breakpoints), penicillin (24.7\% nonsusceptible using parenteral, non-meningitis breakpoints), and several other antimicrobials (Table 5), but telavancin activity was unchanged compared to the full isolate set (Table 2). The MDR $S$. pneumoniae subset was $\geq 95.8$ susceptible to ceftaroline, levofloxacin, linezolid, and vancomycin (Table 5).

\section{Telavancin and comparator activities against BHS and VGS}

The full BHS isolate set and the Streptococcus pyogenes, Streptococcus agalactiae, and Streptococcus dysgalactiae subsets were all $100 \%$ susceptible to telavancin (Table 2) ( $\mathrm{MIC}_{90}$ value, $0.03 \mu \mathrm{g} / \mathrm{mL}$ for each species and the full isolate set). The full VGS isolate set was $99.0 \%$ susceptible to telavancin ( $\mathrm{MIC}_{90}$ value, $0.03 \mu \mathrm{g} / \mathrm{mL}$ ) (Table 2). The $\mathrm{MIC}_{90}$ values for the full BHS and VGS isolate sets did not vary by more than twofold when the data were stratified by continent (data not shown). These data were identical or nearly identical to the corresponding values observed for analogous isolate sets collected and tested from 2011 through 2014. ${ }^{10,16-19}$ MIC data for comparator antimicrobials tested against the full BHS and VGS isolate sets are shown in Supplementary Table S4. The $\mathrm{MIC}_{90}$ value for the MDR BHS subset $(0.03 \mu \mathrm{g} / \mathrm{mL})$ was unchanged compared to the full isolate set, and the $\mathrm{MIC}_{90}$ value for the MDR VGS subset $(0.06 \mu \mathrm{g} / \mathrm{mL})$ only increased twofold compared to the full isolate set (Table 2).

\section{Discussion}

Using the revised MIC testing method for lipoglycopeptides that includes polysorbate 80 , several surveillance studies have reported on telavancin activity against isolates collected worldwide from 2011 to $2014 .^{10,16-19}$ This study extends telavancin global surveillance data for Gram-positive pathogens to include isolates collected from 2015-2017.

These data demonstrate that since 2011, there has been little or no change in telavancin activity against several important Gram-positive pathogen groups that include MRSA, CoNS, vancomycin-susceptible E. faecalis, S. pneumoniae, VGS, and BHS.

The excellent activity of telavancin against ceftarolinenonsusceptible and ceftaroline-resistant $S$. aureus isolates (100\% susceptible) is also noteworthy, given that ceftaroline susceptibility varied by continent for the MRSA and MDR MRSA subsets, with the lowest ceftaroline susceptibility rates being observed in Latin America and the Asia-Pacific region. This finding agrees with previous reports that demonstrated differences in ceftaroline activity against MRSA isolates stratified by geography due to the presence of specific less-susceptible lineages. ${ }^{20-23}$

Importantly, the presence of an MDR phenotype had minimal or no impact on telavancin activity against most of the tested species and groups. As expected, the only exceptions to this finding were the subsets of MDR Enterococcus spp., in which VanA and vancomycin resistance were especially prevalent.

In conclusion, we have extended previous surveillance results and documented the sustained in vitro antimicrobial activity and spectrum of telavancin-many years after its 
clinical approval-against Gram-positive clinical isolates collected worldwide over 7 years, from 2011 through 2017, including ceftaroline-nonsusceptible isolates.

\section{Acknowledgments}

The authors express their appreciation to JMI Laboratories staff members for scientific and editorial assistance during this study.

\section{Disclosure Statement}

JMI Laboratories contracted to perform services in 2017 for Achaogen, Allecra Therapeutics, Allergan, Amplyx Pharmaceuticals, Antabio, API, Astellas Pharma, AstraZeneca, Athelas, Basilea Pharmaceutica, Bayer AG, Becton, Dickinson and Co., Boston Pharmaceuticals, CEM-102 Pharma, Cempra, Cidara Therapeutics, Inc., CorMedix, CSA Biotech, Cutanea Life Sciences, Inc., Entasis Therapeutics, Inc., Geom Therapeutics, Inc., GSK, Iterum Pharma, Medpace, Melinta Therapeutics, Inc., Merck \& Co., Inc., MicuRx Pharmaceuticals, Inc., N8 Medical, Inc., Nabriva Therapeutics, Inc., NAEJA-RGM, Novartis, Paratek Pharmaceuticals, Inc., Pfizer, Polyphor, Ra Pharma, Rempex, Riptide Bioscience, Inc., Roche, Scynexis, Shionogi, Sinsa Labs, Inc., Skyline Antiinfectives, Sonoran Biosciences, Spero Therapeutics, Symbiotica, Synlogic, Synthes Biomaterials, TenNor Therapeutics, Tetraphase, The Medicines Company, Theravance Biopharma, VenatoRx Pharmaceuticals, Inc., Wockhardt, Yukon Pharma, Zai Laboratory, and Zavante Therapeutics, Inc. There are no speakers' bureaus or stock options to declare.

\section{Funding Information}

This study was performed by JMI Laboratories and supported by Theravance Biopharma R\&D, Inc., which included funding for services related to preparing this article.

\section{Supplementary Material}

Supplementary Table S1

Supplementary Table S2

Supplementary Table S3

Supplementary Table S4

\section{References}

1. Karlowsky, J.A., K. Nichol, and G.G. Zhanel. 2015. Telavancin: mechanisms of action, in vitro activity, and mechanisms of resistance. Clin. Infect. Dis. 61:S58-S68.

2. Sweeney, D., D.L. Shinabarger, J.I. Smart, J. Bruss, and C.M. Pillar. 2017. Evaluation of the bactericidal activity of telavancin against Staphylococcus aureus using revised testing guidelines. Diagn. Microbiol. Infect. Dis. 89: 83-85.

3. Higgins, D.L., R. Chang, D.V. Debabov, J. Leung, T. Wu, K.M. Krause, E. Sandvik, J.M. Hubbard, K. Kaniga, D.E. Schmidt, Jr., Q. Gao, R.T. Cass, D.E. Karr, B.M. Benton, and P.P. Humphrey. 2005. Telavancin, a multifunctional lipoglycopeptide, disrupts both cell wall synthesis and cell membrane integrity in methicillin-resistant Staphylococcus aureus. Antimicrob. Agents Chemother. 49:1127-1134.

4. VIBATIV Package Insert. 2016. Package insert. Available at www.vibativ.com (accessed January 2, 2018).
5. Pushkin, R., S.L. Barriere, W. Wang, G.R. Corey, and M.E. Stryjewski. 2015. Telavancin for acute bacterial skin and skin structure infections, a post hoc analysis of the phase 3 ATLAS trials in light of the 2013 FDA guidance. Antimicrob. Agents. Chemother. 59:6170-6174.

6. Torres, A., E. Rubinstein, G.R. Corey, M.E. Stryjewski, and S.L. Barriere. 2014. Analysis of Phase 3 telavancin nosocomial pneumonia data excluding patients with severe renal impairment and acute renal failure. J. Antimicrob. Chemother. 69:1119-1126.

7. Rubinstein, E., G.R. Corey, M.E. Stryjewski, and Z.A. Kanafani. 2011. Telavancin for the treatment of serious grampositive infections, including hospital acquired pneumonia. Expert Opin. Pharmacother. 12:2737-2750.

8. Niederman, M.S., P.C. Lee, S.L. Barriere, C.N. Barnes, and B. Castaneda-Ruiz. 2019. Telavancin in hospital-acquired and ventilator-associated pneumonia (HAP/VAP) caused by Staphylococcus aureus: post hoc analysis of 2 randomized, controlled trials. Infect. Dis. Ther. 8:445-452.

9. Sandrock, C.E., and A.F. Shorr. 2015. The role of telavancin in hospital-acquired pneumonia and ventilator-associated pneumonia. Clin. Infect. Dis. 61(Suppl 2):S79-S86.

10. Duncan, L.R., H.S. Sader, J.I. Smart, R.K. Flamm, and R.E. Mendes. 2017. Telavancin activity in vitro tested against a worldwide collection of gram-positive clinical isolates (2014). J. Glob. Antimicrob. Resist. 10:271-276.

11. Magiorakos, A.P., A. Srinivasan, R.B. Carey, Y. Carmeli, M.E. Falagas, C.G. Giske, S. Harbarth, J.F. Hindler, G. Kahlmeter, B. Olsson-Liljequist, D.L. Paterson, L.B. Rice, J. Stelling, M.J. Struelens, A. Vatopoulos, J.T. Weber, and D.L. Monnet. 2012. Multidrug-resistant, extensively drugresistant and pandrug-resistant bacteria: an international expert proposal for interim standard definitions for acquired resistance. Clin. Microbiol. Infect. 18:268-281.

12. Clinical and Laboratory Standards Institute (CLSI). 2018. M07Ed11. Methods for Dilution Antimicrobial Susceptibility Tests for Bacteria That Grow Aerobically; Approved Standard. 11th ed. Clinical and Laboratory Standards Institute, Wayne, PA.

13. Farrell, D.J., R.E. Mendes, P.R. Rhomberg, and R.N. Jones. 2014. Revised reference broth microdilution method for testing telavancin: effect on MIC results and correlation with other testing methodologies. Antimicrob. Agents Chemother. 58:5547-5551.

14. Clinical and Laboratory Standards Institute (CLSI). 2018. M100Ed28. Performance Standards for Antimicrobial Susceptibility Testing: 28th Informational Supplement. Clinical and Laboratory Standards Institute, Wayne, PA.

15. The European Committee on Antimicrobial Susceptibility Testing (EUCAST). 2018. Breakpoint tables for interpretation of MICs and zone diameters. Version 8.0, January 2018. Available at www.eucast.org/fileadmin/src/media/PDFs/ EUCAST_files/Breakpoint_tables/v_8.0_Breakpoint_Tables .pdf (accessed January 2, 2018).

16. Mendes, R.E., D.J. Farrell, H.S. Sader, R.K. Flamm, and R.N. Jones. 2015. Baseline activity of telavancin against Gram-positive clinical isolates responsible for documented infections in U.S. hospitals (2011-2012) as determined by the revised susceptibility testing method. Antimicrob. Agents Chemother. 59:702-706.

17. Mendes, R.E., H.S. Sader, R.K. Flamm, D.J. Farrell, and R.N. Jones. 2015. Telavancin activity when tested by a revised susceptibility testing method against uncom- 
monly isolated Gram-positive pathogens responsible for documented infections in hospitals worldwide (20112013). J. Global Antimicrob. Res. 3:36-39.

18. Mendes, R.E., D.J. Farrell, H.S. Sader, J.M. Streit, and R.N. Jones. 2015. Update of the telavancin activity in vitro tested against a worldwide collection of Grampositive clinical isolates (2013), when applying the revised susceptibility testing method. Diagn. Microbiol. Infect. Dis. 81:275-279.

19. Mendes, R.E., R.K. Flamm, D.J. Farrell, H.S. Sader, and R.N. Jones. 2016. Telavancin activity tested against Grampositive clinical isolates from European, Russian and Israeli hospitals (2011-2013) using a revised broth microdilution testing method: redefining the baseline activity of telavancin. J. Chemother. 28:83-88.

20. Biedenbach, D.J., R.A. Alm, S.D. Lahiri, E. Reiszner, D.J. Hoban, D.F. Sahm, S.K. Bouchillon, and J.E. Ambler. 2016. In vitro activity of ceftaroline against Staphylococcus aureus isolated in 2012 from Asia-Pacific countries as part of the AWARE surveillance program. Antimicrob. Agents Chemother. 60:343-347.
21. Flamm, R.K., H.S. Sader, and R.N. Jones. 2014. Ceftaroline activity tested against contemporary Latin American bacterial pathogens (2011). Braz. J. Infect. Dis. 18:187-195.

22. Sader, H.S., R.K. Flamm, J.M. Streit, C.G. Carvalhaes, and R.E. Mendes. 2018. Antimicrobial activity of ceftaroline and comparator agents tested against organisms isolated from patients with community-acquired bacterial pneumonia in Europe, Asia, and Latin America. Int. J. Infect. Dis. 77:82-86.

23. Sader, H.S., P.R. Rhomberg, T.B. Doyle, R.K. Flamm, and R.E. Mendes. 2018. Evaluation of the revised ceftaroline disk diffusion breakpoints when testing a challenge collection of methicillin-resistant Staphylococcus aureus isolates. J. Clin. Microbiol. 56:e00777-18.

Address correspondence to: Leonard R. Duncan, PhD JMI Laboratories 345 Beaver Kreek Centre, Suite A North Liberty, IA 52317

USA

E-mail: leonard-duncan@jmilabs.com 